\title{
Re: Postoperative Surgical-Site Hemorrhage After Kidney Transplantation: Incidence, Risk Factors, and Outcomes
}

\author{
Hachem $L D^{1}$, Ghanekar $A^{1,2}$, Selzner $\mathrm{M}^{1,2}$, Famure $0^{1,3}, \mathrm{Li} \mathrm{Y}^{1}$, Kim SJ $\mathrm{J}^{1,3,4}$ \\ 'The University Health Network, Toronto General Hospital, Multi-Organ Transplant Program, Toronto, Canada \\ ${ }^{2}$ University of Toronto Faculty of Medicine, Department of Surgery, Division of General Surgery, Toronto, Canada \\ ${ }^{3}$ University of Toronto, Department of Medicine, Division of Nephrology, Toronto, Canada \\ ${ }^{4}$ University of Toronto, Institute of Health Policy, Department of Management and Evaluation, Toronto, Canada
}

Transpl Int 2017;30:474-483. doi: 10.1111/tri.12926.

\section{EDITORIAL COMMENT}

In this single center retrospective study, the authors have investigated the risk factors and outcomes of surgical site hemorrhage (SSH) occurred within 3 days posttransplant over a 12-year period among 1203 kidney recipients. The reported incidence of SSH was 4.9\% in which the majority of events have occurred in the first postoperative day (89.8\%). Deceased donor transplants and lower recipient body mass index were found to be the biggest risk factors for postoperative SSH besides longer cold ischemia times. Preoperative chronic anticoagulation or antiplatelet therapy has led to an increased risk for postoperative SSH, however, which was not statistically significant. Also, postoperative SSH has resulted with an increased risk for graft and patient loss especially in patients who have required transfusions or reoperation. Besides careful application of meticulous hemostatic techniques during procurement, back-table and in the recipient surgery, identification of such high-risk patients prior to transplantation will lead to better patient care in the posttransplant period.

Yarkın Kamil Yakupoğlu, MD

๑Copyright 2017 by the Association of Urological Surgery / Journal of Urological Surgery published by Galenos Publishing House. 